\title{
HOW INTEGRATED IS INTEGRATED LOGISTICS?
}

\author{
PJ Pretorius ${ }^{1}$
}

Description: A model is constructed from the necessary conditions derived from the definition of integrated logistic support that suggests how business logistics and logistics engineering have to co-exist and be integrated to achieve integrated logistics.

\begin{abstract}
:
Industry and academia still have a major problem in grasping the extent and relationships of all functions involved in integrated logistics. This is because business logistics and logistics engineering developed separately, each with their own following, resulting in the two so-called different disciplines ignoring each other.

By analysing the definition of integrated logistic support, it is possible to identify the necessary conditions for an integrated logistics model. From these necessary conditions, a model of the management functions and technical activities is constructed to suggest the purpose and place of all logistics functions to work in an integrated way towards the goal of the organisation. The model suggests that logistics engineering and business logistics are both required in the organisation and that it is of vital importance that these functions are executed in unison. This model is different to previous models in that it approaches logistics from the organisations viewpoint rather than from a logistics viewpoint.
\end{abstract}

Keywords: Integrated logistics support, logistics engineering, operational logistics, business logistics. 
The goal of any profit-seeking organisation is to make money (Goldratt, 1990:12). It is therefore necessary to approach all management and technical activities from this basic principle. Anything that does not contribute to reaching the goal, is a waste of time and effort. This is also true of logistics within the organisation.

One of the main reasons why it is necessary to discuss the integrated nature of logistics is because no organisation can afford to operate without close-knit integration amongst all the business functions. Unfortunately, there is still a wide gap between the business logistics and the logistics engineering. What is important is to get all logistic functions working together so that the organisation can make more money, now and in the future.

\section{Integrated logistic support}

Integrated logistic support (ILS) is defined as "a disciplined, unified and iterative approach to the management and technical activities necessary to (1) integrate support considerations into system and equipment design; (2) develop support requirements that are related consistently to readiness objectives, to design, and to each other; (3) acquire the required support; and (4) provide the required support during the operational phase at minimum cost" (Blanchard, 1992:13).

There are two distinct observations that can be made from the definition. The first is that integrated logistic support considers management and technical activities as mutually supportive and equally important in achieving the objectives. This constitutes the first necessary condition for integrated logistic support. The second observation is that there is a logic sequence in the objectives e.g. support cannot be acquired unless it was developed. The second necessary condition is therefore that a life cycle approach is to be followed to achieve each of the objectives, thereby ensuring integrated logistic support over the total life cycle. It can thus be derived that in order to construct an integrated logistic support model, the aforementioned necessary conditions must serve as the basis of the model.

\section{Business Logistics}

Blanchard (1992:3) quotes the Council of Logistic Management definition for business logistics as "... the process of planning, implementing and controlling the cost effective flow and storage of raw materials, in-process inventory, finished goods and related information from point of origin to point of consumption for the purpose of conforming to customer requirements." This definition indicates an orientation towards the customer as well as the suppliers as shown in Figure 1, demonstrating the business logistic activities applicable to inbound and outbound logistics (Balou, 1992:18).

Lambert and Stock (1993:5) also include activities such as customer service, demand forecasting, return goods handling, parts and service support as business logistic activities in addition to those indicated by Balou. From this it is clear that business logistics has very strong interfaces with the marketing function through the physical distribution component of the marketing mix (Lambert and Stock, 1993:42,44). 


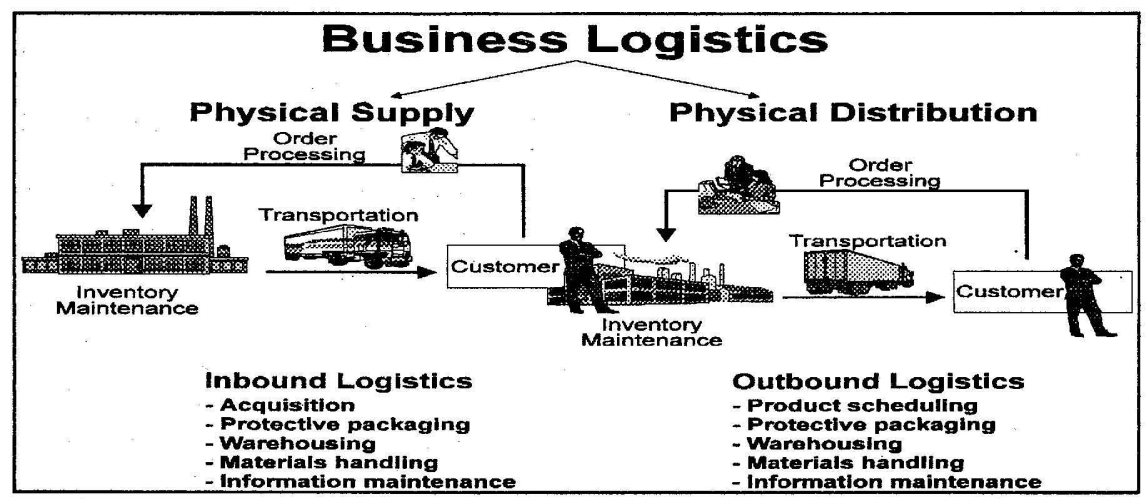

Figure 1

\section{$4 \quad$ Logistics engineering}

Nowadays the term 'business process re-engineering' is heard frequently, implying that business processes are to be engineered i.e. constructed in an engineering like manner. In the same way logistics should be engineered i.e. logistics engineering, before business logistics can come into place. The purpose of logistics engineering is to ensure that whilst designing a system all operational considerations are taken into account in order to make that design supportable from a logistical viewpoint. Furthermore, logistics engineering ensures that all resources that will be required by the system during its operations phase for operations and support are designed and available when the system goes into operation. "In essence, logistics engineering covers (1) the design of the prime mission equipment for supportability, and (2) the design of the overall support capability for the system." (Blanchard, 1992:14)

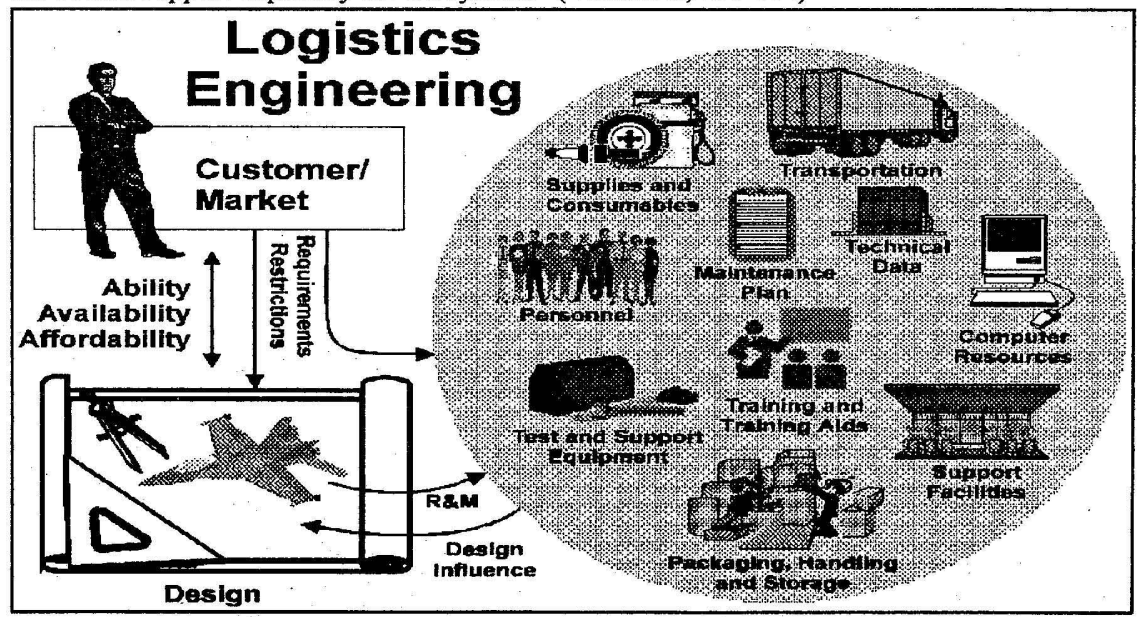

Figure 2 
These two primary goals are achieved by vigorously pursuing design activities that considers the customer/market environment, that considers restrictions this environment places on the design and support system, that ensures the market requirements are met. In order to have a total system, the support system is designed and implemented as the logistic elements as indicated in Figure 2. These two primary goals of logistics engineering clearly demonstrates a strong marketing orientation. What is aimed at when striving for a logistically supportable system is system ability, system availability and system affordability. If we have a capable system (that runs smoothly because of logistics), available when required (through a logistic support system) and cost effective (because it was designed to be that way), the organisation can make more money.

Logistics engineering is clearly the vehicle used to achieve the first two objectives of integrated logistic support, especially on the technical activity side. However, it cannot be achieved without considering the operational environment, providing for the third necessary condition. There may be some doubt as to whether business logistics will achieve the final two objectives, due to the strong maintenance connotation to logistics engineering. Consider for the moment that business logistics will not achieve the final two objectives of integrated logistics support and define a new category, namely operational logistics.

\section{$5 \quad$ Operational logistics}

Operational logistics (i.e. logistic activities performed during the preparation for and operational phases of the life cycle) can be defined as (analogue to ILS definition) those management and technical activities necessary to (1) acquire the required support; and (2)

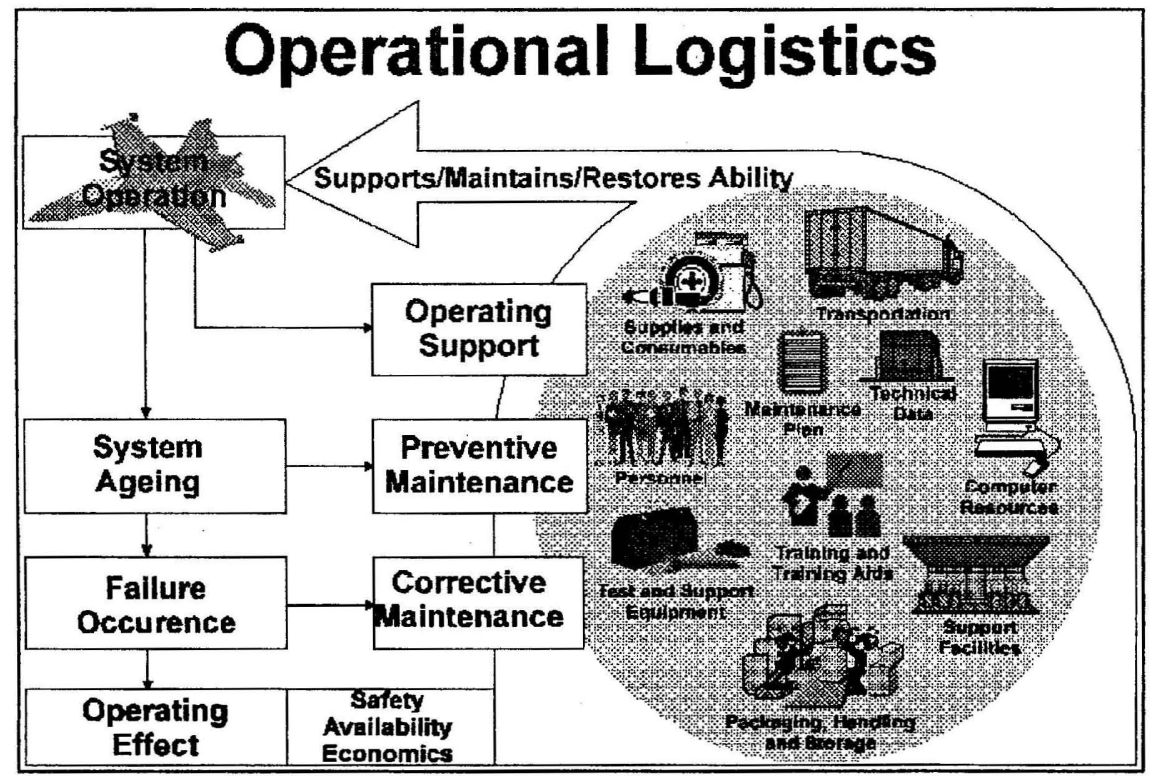

Figure 3 
provide the required support during the operational phase at minimum cost. This can only be successful if the output from the logistics engineering is used. Figure 3 indicates what is implicated in operational logistics. However, in order to achieve the second objective, providing the support, changes will inevitably take place, which will again require logistics engineering. From this follows the fourth necessary condition for the model, namely that logistics engineering should be available during the operational phase until phase out in order to support changes taking place in the design.

\section{Integration of logistics engineering and operational logistics}

These two categories, logistics engineering and operational logistics can now be integrated into one model (Figure 4) using the necessary conditions. It is clear that all four necessary conditions are met, namely considering both management and technical activities, the life cycle approach, engineering logistics considering the operational environment and logistics engineering support existing until phase out.

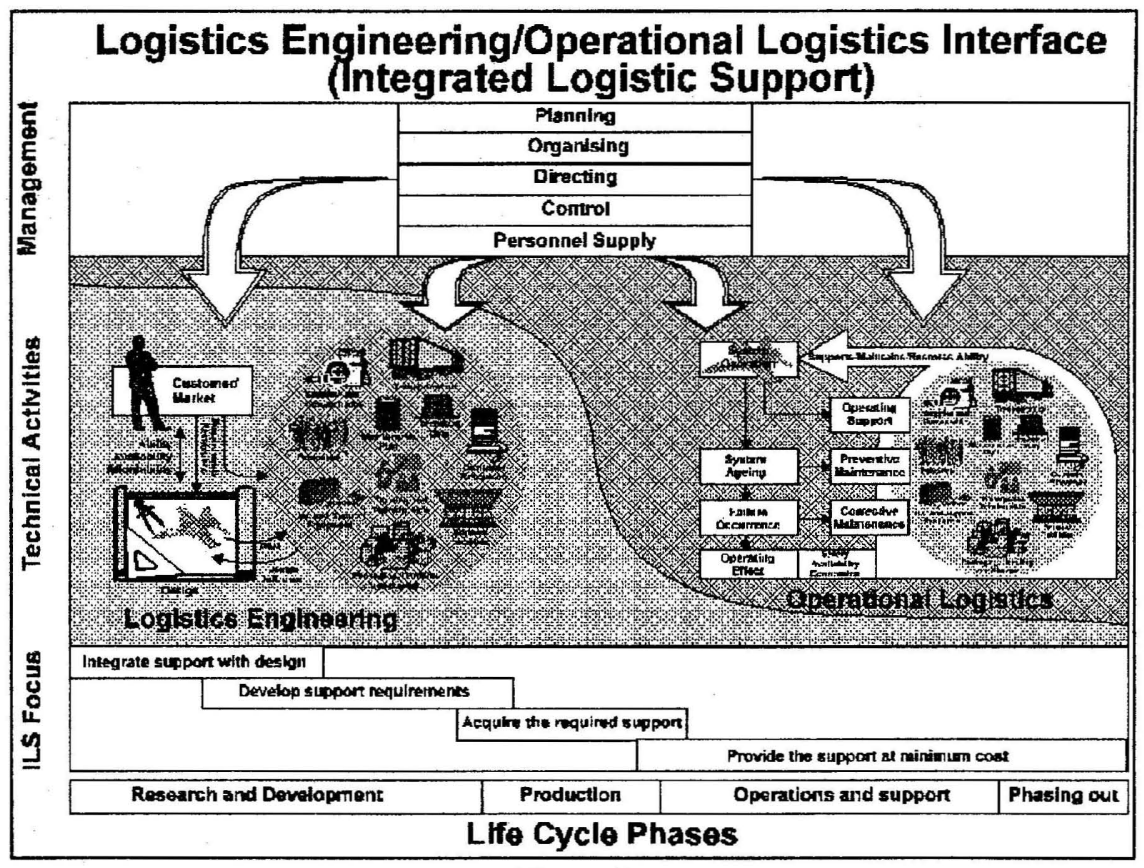

Figure 4

This model can now be used for any system, irrespective of its nature. This model is as applicable to a military system as it is to an organisation. It may be that the terms used to describe different functions within the different systems may vary, but in essence are aimed at achieving the same function. It is fairly easy to visualise how this model can be applicable to a military system. To aid in the visualisation as to how this model is applicable to an organisation 
is to consider that an organisation is also designed and engineered, with all its supporting functions in order to operate it to achieve production, along with a preventive and corrective maintenance function.

This model is applicable on two levels of any organisation. First of all, on the engineering and operation of the organisation itself and secondly on the products and/or services the organisation delivers to the market. When engineering the logistics for the product and/or service, it is imperative to integrate the operational logistics of the product/service with that of the organisation and the market environment.

\section{The role of business logistics}

It is quite clear that business logistics is only one of many needed functions within the operational logistics and not the single key factor that makes or breaks the organisation. All the parts have to work together well for an organisation to be successful. Where the proposed model focuses strongly on the technical activities of the physical logistic elements involved, the emphasis of business logistics is more on the management of the operational logistics, including the business logistic functions required for the maintenance support. Therefore business logistics has a major part to play within the operational environment, while at the same time getting involved in the logistics engineering phases, in order to support the organisation as a whole in achieving its goal.

\section{Conclusion}

The conclusion that is drawn is that logistics engineering have in the past focused too much on the technical activities and elements of product systems, disregarding the management processes that are needed to be engineered for the operational phase of both the product systems and the organisation. Also, business logistics focused too much on the management processes of the organisation that were not well engineered or not engineered at all.

Furthermore, the maintenance support and the associated business logistics required by the maintenance function were also totally ignored. The time has come to accept integrated logistic support as the only definition for total logistics involving both management and technical activities. In order to be competitive management needs to closely integrate all functions of the organisation. Logistics in itself has no purpose. Logistics supporting an organisation in an integrated way provides an impetus to achieving the goal, MAKING MONEY.

\section{References}

Blanchard, B.S., 1992, Logistics engineering and management, Fourth Edition, Prentice Hall, Englewood Cliffs, New Jersey

Balou, R.H., 1987, Basic business logistics, Second Edition, Prentice Hall, Englewood Cliffs, New Jersey

Goldratt, E.M., 1990, The Haystack Syndrome, North River Press, New York

Lambert, D.M., Stock, J., 1993, Strategic Logistics Management, Third Edition, IRWIN, Homewood, Illinois 